\title{
The value of maspin and PD-L1 expression and peritumoral lymphocytic infiltration in breast tumors
}

\author{
Tuncel $\mathrm{F}^{1}$, Bozkurt $\mathrm{F}^{1}$, Berkesoglu $\mathrm{M}^{2}$ \\ Mersin University Medical Faculty, Medical Pathology Department, Mersin, Turkey. ferahdaloglu@hotmail.com
}

\begin{abstract}
OBJECTIVE: Breast cancer is the most common type of cancer in women worldwide. Our aim is to evaluate the importance of immunotherapy in breast cancer cases by using PD-L1 expression and to determine the effect of Maspin expression and lymphocytic density on predicting the prognosis.

METHODS: A total of 200 breast cancer cases with different histological types were included in the study.

The expression of PD-L1 and Maspin in these tumors were evaluated, and the lymphocytic infiltration density was examined.

RESULTS: Expression of PD-L1 in tumor cells was significantly higher in "medullary carcinoma" and grade 3 tumors. Expression of PD-L1 in inflammatory cells was increased in the group of "other types" and grade 3 tumors. Maspin expression was observed in 93 cases and was higher in "lobular carcinoma" and high grade tumors. In our study, a significant correlation was found between lymphocytic density score and histological grade and PD-L1 expression.

CONCLUSION: In our study, PD-L1 expression was detected in breast cancer, and was associated with triple negativity and high grade. Our results show that the Maspin expression and lymphocyte density are associated with the prognosis (Tab. 5, Fig. 4, Ref. 44). Text in PDF www.elis.sk

KEY WORDS: Breast carcinoma, PD-L1, Maspin, lymphocyte infiltration.
\end{abstract}

\section{Introduction}

Breast cancer is the most common cancer type in women worldwide and is the leading cause of cancer death (1). The use of screening methods, innovations in diagnosis and treatment reduce the mortality rates related to breast cancer. However, the heterogeneous nature of breast cancer affects the response to treatment (2). The importance of the immune system in the progression of breast cancer was emphasized by showing the effect of tumor microenvironment on survival and response to treatment (3). In recent years, immunotherapies that target immune control point molecules such as cytotoxic T-lymphocyte-associated antigen 4 (CTLA-4) and programmed cell death protein-1 (PD-1) have emerged as new treatment modalities (2).

PD-1 is an immune suppressive molecule from the B7-CD28 family that regulates $\mathrm{T}$ cell activation (4).PD-1 is expressed on tumor infiltrating lymphocytes (TIL), CD4+ T cells, B cells, natural killer cells, monocytes and dendritic cells. PD-1 has two ligands, PD-L1 (B7-H1, CD274) and PD-L2 (B7-DC, CD273) (5). PD$\mathrm{L} 1$ is expressed in hematopoietic cells and some tumor cells (6).

${ }^{1}$ Mersin University Medical Faculty, Medical Pathology Department, Mersin, Turkey, and ${ }^{2}$ Mersin University Medical Faculty, General Surgery Department, Mersin, Turkey

Address for correspondence: F. Tuncel, Mersin University Hospital, PO: 33130, Mersin, Turkey.

Phone: +90.505 .5239059 , Fax: +90.324 .3610073$
Expression of PD-L1 in tumor cells is explained by two mechanisms. In the primary mechanism, tumor cells activate PD-L1 expression with various oncogenic signal pathways such as phosphoinosidide 3-kinase / protin kinase B (PI3K / AKT), extracellular-signal-regulator protein kinase / mitogen-activating kinase (Erk / MAPK), Janus kinase (JAK2) / STAT (7). The second mechanism (adaptive immune resistance) leads to PD-L1 expression on tumor cells in response to specific cytokines, especially IFN- $\gamma$. IFN-induced expression of PD-L1 is more common in most cancer histologies than in structural expression. This expression occurs mostly in T cell-rich and invasive areas of the tumor. In some tumors, there is a significant correlation between PD-L1 expression, T-cell infiltration and IFN- $\gamma$ levels in intrinsic immune resistance (8).

PD-1 reduces anti-tumor T cell activity after binding to its ligands and facilitates tumor escape from the immune system (9). In many solid tumors such as melanoma, renal cell carcinoma and lung cancer, blockade of the PD-1 / PD-L1 axis has been found to increase survival (10-12).

Maspin is a member of the serine protease inhibitor family. It was first described in normal breast tissue in myoepithelial cells and later in breast cancers (13). Studies have shown that maspin plays a role in the inhibition of metastasis and invasion of cancer cells. In addition, maspin protein has an inhibitory effect on angiogenesis in cancers. However, the mechanism of Maspin function and its role in cancer is still uncertain and there is insufficient information about it (14). 
In studies conducted on the role and importance of maspin protein in breast cancer, conflicting results have been observed (14, 15). Studies have shown that nuclear maspin expression is associated with well-differentiated tumors and good prognosis, while cytoplasmic maspin expression is associated with poor prognosis in many cancers $(16,17)$.

Maspin is a tumor suppressor protein found in normal breast myoepithelial cells. Its expression is known to decrease in breast cancer progression, and decreased expression is associated with a higher risk of distant metastasis $(18,19)$.

Immune system and tumor microenvironment play an important role in the progression of breast cancer (3). Medullary carcinoma, which is one of the triple negative breast cancers, has a relatively good prognosis that is partially attributed to the lymphocytic response (20). The vast majority of malignant breast tumors contain varying degrees of lymphocytic infiltration in their stroma (21).

Our aim in this study is to detect PD-L1 and maspin protein expressions in different types of breast cancers, to evaluate the lymphocytic density of different types of tumors comparatively and to investigate their relationship with clinicopathological parameters. Thus, the importance of immunotherapy in cases with breast cancer will be evaluated and the effect of maspin expression and lymphocytic density on predicting prognosis will be determined.

\section{Materials and methods}

\section{Case selection}

200 cases diagnosed with breast cancer in mastectomy specimens evaluated between 2015-2019 in Mersin University Medical Faculty Medical Pathology Department were included in the study. 115 of the cases were invasive ductal carcinoma ( 25 histological grade 1, 40 histological grade 2, 50 histological grade 3), 35 were invasive lobular carcinoma, and 25 were medullary carcinoma/ /invasive carcinoma with medullary features. 25 cases included other histological types (tubular, cribriform, micropapillary, mucinous carcinoma). Age, gender, tumor size, lymph node metastasis, lymphovascular invasion, pathological stage information of the cases were obtained from the hospital information system and corresponding pathology reports.

This study was approved by Mersin University Clinical Research Ethics Committee with the decision numbered 2019/34 on $23 / 01 / 2019$.

\section{Immunohistochemical staining}

Sections were taken from the prepared paraffin blocks and staining was performed with PD-L1 and Maspin antibody. This staining was done in Ventana Benchmark-XT automatic staining device (Ventana Medical Systems; Roche; USA) using anti-PDL1 (SP142), anti-Maspin (ab182785) antibodies and ultraView Universal DAB Detection kit. Placental tissue for PD-L1 and esophageal squamous cell carcinoma tissue sample for Maspin antibody were used as positive external control.

\section{Immunohistochemical assessment}

Immunohistochemically stained slides were evaluated by 2 pathologists for each case. Expression of PD-L1 was evaluated separately in both tumor cells and inflammatory cell groups accompanying the tumor. Cytoplasmic or membranous staining was considered significant, and the percentage of positive stained tumor cells and inflammatory cells was determined.

PD-L1 expression is graded as 0 if tumor cells do not have staining or have staining below $1 \%$, score 1 if they show $1-5 \%$ staining, score 2 if they have $5-50 \%$ staining, score 3 if $50 \%$ or more of tumor cells show staining. PD-L1 expression was considered positive for SP142 clone of tumor cells with scores 2 and 3 staining. In inflammatory cells, no staining or below $1 \%$ staining were considered PD-L1 negative and, $1 \%$ or more staining is considered to be PD-L1 positive (22).

Expression was determined as positive in the presence of staining in more than $10 \%$ of tumor cells with maspin antibody. Cytoplasmic, nuclear or cytoplasmic and nuclear staining were accepted as positive (23).

In the evaluation of the lymphocytic density of the tumors, the score was graded as 1 if the lymphocytic response was present in less than $10 \%$ of the area that contains tumor cells, graded as 2 if that area percentage was between $10-30 \%$, and graded as 3 for area percentage of $30 \%$ and above.

Tab. 1.Clinicopathological features of breast cancer cases.

\begin{tabular}{lc}
\hline \multirow{2}{*}{ Clinicopathologic features } & Total $\mathrm{n}=200(100 \%)$ \\
\cline { 2 - 2 } Age Median (range) & $\mathrm{n}(\%)$ \\
$\leq 50$ years & $55.96 \pm 13.09(27-85)$ \\
$>50$ years & $128(64)$ \\
\hline Gender & $197(98.5)$ \\
Female & $3(1.5)$ \\
Male & $115(57.5)$ \\
Tumor type & $35(17.5)$ \\
Invasive ductal carcinoma (NST) & $25(12.5)$ \\
Invasive lobular carcinoma & \\
Medullary carcinoma/invasive carcinoma & $25(12.5)$ \\
$\quad$ with medullary features & $31(15.5)$ \\
Other types & $80(40)$ \\
\hline Histologic grade & $89(44.5)$ \\
Grade I & \\
Grade II & $56(28)$ \\
Grade III & $123(61.5)$ \\
\hline Tumor size & $21(10.5)$ \\
$\leq 2$ cm &
\end{tabular}




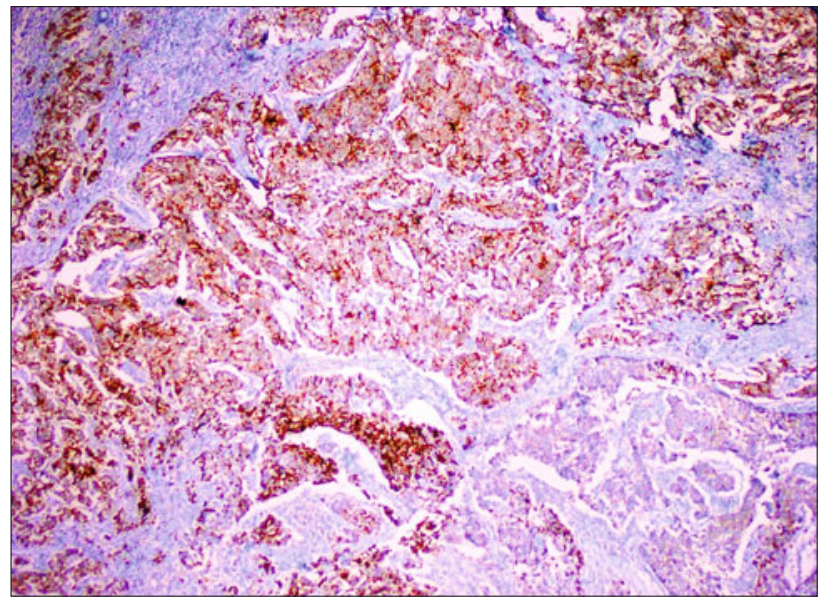

Fig. 1. PD-L1 expression in tumor cells (x 40).

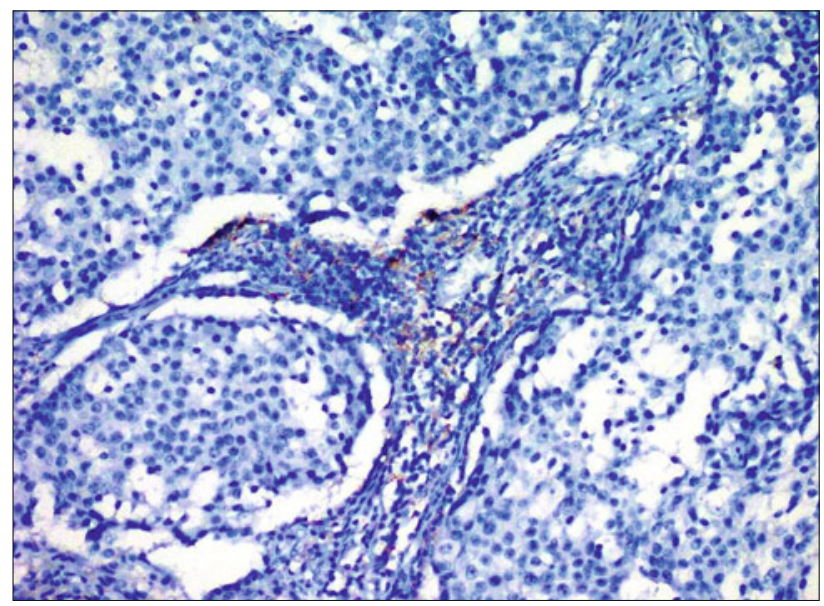

Fig. 2. PD-L1 expression in inflammatory cells(x 200).

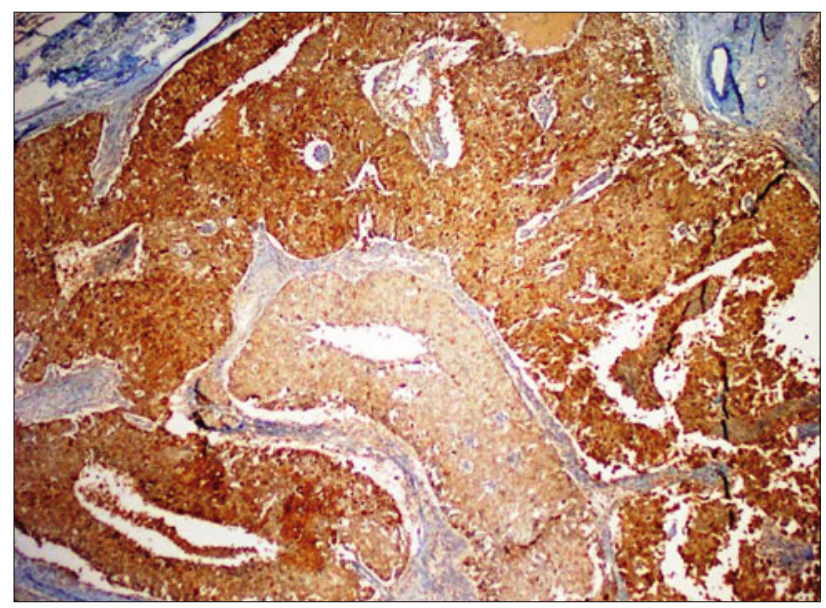

Fig. 3. Cytoplasmic maspin expression(x 40).

\section{Statistical analysis}

All statistical analyses were done with STATISTICA Version 13.5.0.17 17 (TIBCO Software Inc. (2017)) program. The normal distribution assumption was checked by the Shapiro Wilk test. Age,

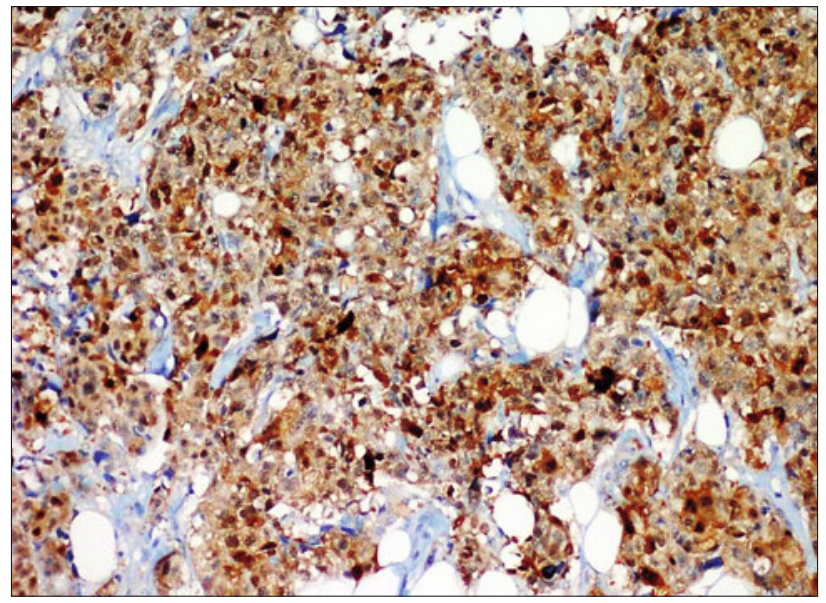

Fig. 4. Cytoplasmic and nuclear maspin expression( x200).

minimum, maximum and mean \pm standard deviation values matching normal distribution and continuous variables that do not show normal distribution are summarized, with the median and quarterly differences (Q3-Q1), the categorical variance of clinicopathological features, PD-L1 expressions, maspin expressions and lymphocytic density scores (summarized asfrequencies [n] and percentage rates (\%)). To investigate the relationships between categorical variables, Chi-Square analysis was performed. As a result of this analysis, taking into account the minimum expected values and their rates; the $p$ values of Pearson Chi-square test, Fisher's Exact test or Likelihood Ratio test were used. The ratios of variables with statistically significant relationship in cross tables with more than two rows or columns were compared with two ratios $\mathrm{Z}$ test. Kruskal-Walis test, one of the non-parametric methods, was used to compare the medians of more than two independent groups.

Statistical significance level of $(p) \leq 0.05$ was accepted for all comparisons.

\section{Results}

This study includes 200 cases diagnosed with breast carcinoma. The age of the patients ranged from 27 to $85(55.96 \pm 13.09)$. The clinicopathological features of the cases are summarized in Table 1.

\section{PD-L1 expression}

PD-L1 expression was evaluated in tumor cells and inflammatory cells that infiltrate the tumor. Patients with a score of +2 and +3 according to the percentage of staining in tumor cells and $1 \%$ or more staining in inflammatory cells were considered expression positive.

PD-L1 expression in tumor cells and its relationship with clinicopathological parameters

Expression of PD-L1 (clone sp142) in tumor cells was detected in $12(6 \%)$ cases (Fig. 1). Five of the cases with expression were diagnosed with invasive ductal carcinoma, 1 with invasive lobular carcinoma and 6 with medullary carcinoma / invasive carcinoma 
Tab. 2. PD-L1 expression in tumor cells and its relationship with clinicopathological parameters.

\begin{tabular}{|c|c|c|c|}
\hline Clinicopathologic parameters & $\begin{array}{c}\text { PD-L1 } \\
\text { negative } \\
\mathrm{n}=188\end{array}$ & $\begin{array}{c}\text { PD-L1 } \\
\text { positive } \\
n=12\end{array}$ & $\mathrm{p}$ \\
\hline \multicolumn{4}{|l|}{ Age } \\
\hline$\leq 50$ years & 69 & 3 & 0.543 \\
\hline$>50$ years & 119 & 9 & \\
\hline \multicolumn{4}{|l|}{ Gender } \\
\hline Female & 185 & 12 & 1.0 \\
\hline Male & 3 & 0 & \\
\hline \multicolumn{4}{|l|}{ Tumor type } \\
\hline Invasive ductal carcinoma (NST) & 110 & 5 & \\
\hline Invasive lobular carcinoma & 34 & 1 & \\
\hline $\begin{array}{l}\text { Medullary carcinoma/invasive carcinoma } \\
\text { with medullaryfeatures }\end{array}$ & 19 & 6 & \\
\hline Other types & 25 & 0 & $0.005^{*}$ \\
\hline \multicolumn{4}{|l|}{ Histologic grade } \\
\hline Grade I & 30 & 1 & \\
\hline Grade II & 80 & 0 & \\
\hline Grade III & 78 & 11 & $0.002 *$ \\
\hline \multicolumn{4}{|l|}{ Tumor size } \\
\hline$\leq 2 \mathrm{~cm}$ & 54 & 2 & \\
\hline $2-5 \mathrm{~cm}$ & 114 & 9 & \\
\hline$>5 \mathrm{~cm}$ & 20 & 1 & 0.812 \\
\hline \multicolumn{4}{|l|}{ Lymphnode metastasis } \\
\hline Present & 85 & 4 & \\
\hline Absent & 103 & 8 & 0.422 \\
\hline \multicolumn{4}{|l|}{ Lymphovascular invasion } \\
\hline Present & 85 & 4 & \\
\hline Absent & 103 & 8 & 0.422 \\
\hline \multicolumn{4}{|l|}{ Lymphocytic infiltration density score } \\
\hline Score $1(<10 \%)$ & 110 & 4 & \\
\hline Score $2(10-30 \%)$ & 44 & 7 & \\
\hline Score $3(\geq 30 \%)$ & 34 & 1 & $0.033^{*}$ \\
\hline
\end{tabular}

$\mathrm{n}-$ number of patients. * Significant $(\mathrm{p}<0.05)$

with medullary features. In our study, the PD-L1 expression rate in patients with medullary carcinoma / invasive carcinoma with medullary features was significantly higher than in others $(p=0.0001)$.

11 of PD-L1 positive tumors were histological grade 3,1 was histological grade 1 . Grade 3 tumor cases had significantly higher percentage of PD-L1 expression positivity $(p=0.0007)$.

A statistically significant relationship was found between PDL1 expression in tumor cells and lymphocytic density score $(\mathrm{p} \leq$ 0.05 ). In cases with lymphocytic density between 10-30\% (score $2)$, PD-L1 expression positivity rate $(58.3 \%)$ was higher than negative $(24.3 \%)$, and this difference between the rates was statistically significant $(p=0.007)$. In cases where the lymphocytic response was score 1 and score 3 , there was no significant difference in terms of PD-L1 expression in tumor cells.

There was no significant correlation between PD-L1 expression in tumor cells and other clinicopathological parameters (lymph node metastasis, lymphovascular invasion, tumor size $)(p>0.05)$ (Tab. 2).

PD-L1 expression in inflammatory cells and its relationship with clinicopathological parameters

Expression of PD-L1 (clone sp142) in inflammatory cells was positive in 45 (22.5\%) cases, and no expression was observed in
Tab. 3. PD-L1 expression in inflammatory cells and its relationship with clinicopathological parameters.

\begin{tabular}{|c|c|c|c|}
\hline Clinicopathologic parameters & $\begin{array}{c}\text { PD-L1 } \\
\text { negative } \\
n=155\end{array}$ & $\begin{array}{c}\text { PD-L1 } \\
\text { positive } \\
n=45\end{array}$ & $\mathrm{p}$ \\
\hline \multicolumn{4}{|l|}{ Age } \\
\hline$\leq 50$ years & 54 & 18 & \multirow{2}{*}{0.525} \\
\hline$>50$ years & 101 & 27 & \\
\hline \multicolumn{4}{|l|}{ Gender } \\
\hline Female & 154 & 43 & \multirow{2}{*}{0.250} \\
\hline Male & 1 & 2 & \\
\hline \multicolumn{4}{|l|}{ Tumor type } \\
\hline Invasive ductal carcinoma (NST) & 98 & 17 & \multirow{4}{*}{$<0.0001^{*}$} \\
\hline Invasive lobular carcinoma & 29 & 6 & \\
\hline $\begin{array}{l}\text { Medullary carcinoma/invasive carcinoma } \\
\text { with medullary features }\end{array}$ & 16 & 9 & \\
\hline Other types & 12 & 13 & \\
\hline \multicolumn{4}{|l|}{ Histologicgrade } \\
\hline Grade I & 27 & 4 & \multirow{3}{*}{$0.023 *$} \\
\hline Grade II & 67 & 13 & \\
\hline Grade III & 61 & 28 & \\
\hline \multicolumn{4}{|l|}{ Tumor size } \\
\hline$\leq 2 \mathrm{~cm}$ & 46 & 10 & \multirow{3}{*}{0.617} \\
\hline $2-5 \mathrm{~cm}$ & 93 & 30 & \\
\hline$>5 \mathrm{~cm}$ & 16 & 5 & \\
\hline \multicolumn{4}{|l|}{ Lymphnode metastasis } \\
\hline Present & 69 & 20 & \multirow{2}{*}{0.993} \\
\hline Absent & 86 & 25 & \\
\hline \multicolumn{4}{|l|}{ Lymphovascular invasion } \\
\hline Present & 70 & 19 & \multirow{2}{*}{0.727} \\
\hline Absent & 85 & 26 & \\
\hline \multicolumn{4}{|l|}{ Lymphocytic infiltration density score } \\
\hline Score $1(<10 \%)$ & 101 & 13 & \multirow{3}{*}{$<0.0001^{*}$} \\
\hline Score $2(10-30 \%)$ & 36 & 15 & \\
\hline Score $3(\geq \% 0 \%)$ & 18 & 17 & \\
\hline
\end{tabular}

155 cases (Fig. 2). Considering the relationship between tumor types and PD-L1 (clone sp142) expression in inflammatory cells, the rate of negative cases in invasive ductal carcinoma was significantly higher than positive $(p=0.0002)$, while the group that contained other tumor types had significantly higher PD-L1 expression positivity rate $(\mathrm{p}=0.0002)$.

In our study, a statistically significant relationship was found between tumor grade and PD-L1 expression in inflammatory cells $(p \leq 0.05)$. In Grade 3 tumors, PD-L1 positivity in inflammatory cells was found to be significantly higher $(\mathrm{p}=0.006)$.

In tumors with a lymphocytic density of $30 \%$ or more (score 3 ), the positivity of PD-L1 expression in inflammatory cells was found to be significantly higher than score 1 and score 2 tumors $(p=0.00001)$. There was no significant correlation between PDL1 expression in inflammatory cells and other clinicopathological parameters ( $p>0.05)$ (Tab. 3).

\section{Maspin expression}

In our study, maspin expression positivity was found in 93 of 200 cases (46.5\%). In 73 (78.5\%) of 93 cases with positive maspin expression, staining was detected only in the cytoplasm (Fig. 3), and $20(21.5 \%)$ in both the cytoplasm and nucleus (Fig. 4). There was no case with only nuclear maspin positivity. 
Tab. 4. Relationship between Maspin expression and clinicopathological parameters.

\begin{tabular}{|c|c|c|c|}
\hline Clinicopathologic parameters & $\begin{array}{c}\text { Maspin } \\
\text { negative } \\
n=107\end{array}$ & $\begin{array}{c}\text { Maspin } \\
\text { positive } \\
n=93\end{array}$ & $\mathrm{p}$ \\
\hline \multicolumn{4}{|l|}{ Age } \\
\hline$\leq 50$ years & 37 & 35 & \multirow{2}{*}{0.653} \\
\hline$>50$ years & 70 & 58 & \\
\hline \multicolumn{4}{|l|}{ Gender } \\
\hline Female & 104 & 93 & \multirow{2}{*}{0.297} \\
\hline Male & 3 & 0 & \\
\hline \multicolumn{4}{|l|}{ Tumor type } \\
\hline Invasive ductal carcinoma (NST) & 67 & 48 & \multirow{4}{*}{$0.033^{*}$} \\
\hline Invasive lobular carcinoma & 13 & 22 & \\
\hline $\begin{array}{l}\text { Medullary carcinoma/invasive carcinoma } \\
\text { with medullary features }\end{array}$ & 10 & 15 & \\
\hline Other types & 17 & 8 & \\
\hline \multicolumn{4}{|l|}{ Histologicgrade } \\
\hline Grade I & 20 & 11 & \multirow{3}{*}{0.252} \\
\hline Grade II & 38 & 42 & \\
\hline Grade III & 49 & 40 & \\
\hline \multicolumn{4}{|l|}{ Tumor size } \\
\hline$\leq 2 \mathrm{~cm}$ & 33 & 23 & \multirow{3}{*}{0.263} \\
\hline $2-5 \mathrm{~cm}$ & 66 & 57 & \\
\hline$>5 \mathrm{~cm}$ & 8 & 13 & \\
\hline \multicolumn{4}{|l|}{ Lymphnode metastasis } \\
\hline Present & 48 & 41 & \multirow{2}{*}{0.913} \\
\hline Absent & 59 & 52 & \\
\hline \multicolumn{4}{|l|}{ Lymphovascular invasion } \\
\hline Present & 52 & 37 & \multirow{2}{*}{0.211} \\
\hline Absent & 55 & 56 & \\
\hline \multicolumn{4}{|l|}{ Lymphocytic infiltration density score } \\
\hline Score $1(<10 \%)$ & 56 & 58 & \multirow{3}{*}{0.341} \\
\hline Score $2(10-30 \%)$ & 31 & 20 & \\
\hline Score $3(\geq 30 \%)$ & 20 & 15 & \\
\hline
\end{tabular}

$\mathrm{n}-$ number of patients. $*$ Significant $(\mathrm{p}<0.05)$

\section{Maspin expression and its relationship with clinicopathological parameters}

48 of 93 cases with maspin expression were diagnosed as invasive ductal carcinoma, 22 were invasive lobular carcinoma, 15 were medullary carcinoma / invasive carcinoma with medullary features, 8 were other types of carcinoma. In our study, a significant relationship was found between tumor types and maspin expression, and it was found that maspin expression was significantly higher in invasive lobular carcinoma $(p=0.03)$. No significant relationship was observed with other clinicopathological parameters $(\mathrm{p}$ $>0.05$ ) (Tab. 4). However, when the median value of maspin expression percentage and tumor grade were compared, it was found that grade 3 tumors had higher maspin expression percentage than grade 1 tumors $(p=0.031)$. Grade 3 tumors had a median maspin expression value of 5, Q1 value of 0 and Q3 value of 55; meanwhile for grade 1 tumors, these values were 0,0 and 10 respectively.

When the maspin staining method was evaluated, cytoplasmic staining was found to be significantly higher in medullary carcinoma / invasive carcinoma with medullary features cases $(\mathrm{p}=0.001)$. In our study, there was no significant relationship between maspin expression and PD-L1 expression in tumor cells and inflammatory cells $(\mathrm{p}>0.05)$.
Tab. 5. Relationship between lymphocytic density score and clinicopathological parameters.

\begin{tabular}{|c|c|c|c|c|}
\hline \multirow[b]{2}{*}{ Clinicopathologic parameters } & \multicolumn{3}{|c|}{ Lymphocytic density score } & \multirow[b]{2}{*}{$\mathrm{p}$} \\
\hline & $\begin{array}{l}\text { Score } 1 \\
\mathrm{n}=114\end{array}$ & $\begin{array}{c}\text { Score } 2 \\
n=51\end{array}$ & $\begin{array}{c}\text { Score } 3 \\
\mathrm{n}=35\end{array}$ & \\
\hline \multicolumn{5}{|l|}{ Age } \\
\hline$\leq 50$ years & 40 & 17 & 15 & \multirow{2}{*}{0.634} \\
\hline$>50$ years & 74 & 34 & 20 & \\
\hline \multicolumn{5}{|l|}{ Gender } \\
\hline Female & 113 & 50 & 34 & \multirow{2}{*}{0.683} \\
\hline Male & 1 & 1 & 1 & \\
\hline \multicolumn{5}{|l|}{ Tumor type } \\
\hline Invasive ductal carcinoma & 62 & 38 & 15 & \multirow{4}{*}{$<0.0001^{*}$} \\
\hline Invasive lobular carcinoma & 33 & 1 & 1 & \\
\hline $\begin{array}{l}\text { Medullary carcinoma/invasive } \\
\text { carcinoma with medullary features }\end{array}$ & 12 & 8 & 5 & \\
\hline Other types & 7 & 4 & 14 & \\
\hline \multicolumn{5}{|l|}{ Histologic grade } \\
\hline Grade I & 22 & 6 & 3 & \multirow{3}{*}{$0.014 *$} \\
\hline Grade II & 52 & 13 & 15 & \\
\hline Grade III & 40 & 32 & 17 & \\
\hline \multicolumn{5}{|l|}{ Tumor size } \\
\hline$\leq 2 \mathrm{~cm}$ & 34 & 15 & 7 & \multirow{3}{*}{0.553} \\
\hline $2-5 \mathrm{~cm}$ & 67 & 30 & 26 & \\
\hline$>5 \mathrm{~cm}$ & 13 & 6 & 2 & \\
\hline \multicolumn{5}{|l|}{ Lymphnode metastasis } \\
\hline Present & 45 & 27 & 17 & \multirow{2}{*}{0.238} \\
\hline Absent & 69 & 24 & 18 & \\
\hline \multicolumn{5}{|l|}{ Lymphovascular invasion } \\
\hline Present & 45 & 29 & 15 & \multirow{2}{*}{0.113} \\
\hline Absent & 69 & 22 & 20 & \\
\hline
\end{tabular}

Lymphocytic density score and its relationship with clinicopathological parameters

In our study, our lymphocytic density scoring detected 114 cases as score 1, 51 cases as score 2, and 35 cases as score 3 .

In invasive ductal carcinoma cases, the number of cases with lymphocytic density score 1 was significantly higher than score 2 , and the number of score 2 cases was significantly higher than score $3(p=0.01, p=0.003)$. In lobular carcinoma, the number of score 1 cases was found to be much higher than the number of score 2 and 3 cases, and this difference was statistically significant ( $\mathrm{p}=$ $0.0001, p=0.0001$ ). The number of cases with lymphocytic density score of 3 in the group containing other carcinomas was significantly higher than the other 2 groups $(p=0.0001, p=0.0003$ ). There was no statistically significant difference between the lymphocytic density score groups in medullary carcinoma $(\mathrm{p}>0.05)$.

A statistically significant relationship was found between lymphocytic density score and grade $(\mathrm{p} \leq 0.05)$. The rate of score 1 cases in Grade 2 tumors is higher than score 2 cases $(\mathrm{p}=0.001)$. In Grade 3 tumors, the rate of score 2 cases was higher than score 1 cases $(p=0.001)$. No relationship was found with other clinicopathological parameters $(p>0.05)$ (Tab. 5).

\section{Discussion}

PD-L1 is a type I transmembrane protein with 290 amino acids encoded by the CD272 gene on the 9th chromosome (24). It is 
known that PD-L1 is expressed in tumor cells and immune cells that infiltrate the tumor (25). Tumor cell expressing PD-L1 inhibits T cell function and prevents tumor eradication. This situation can be prevented by anti-PD-1 / PD-L1 immunotherapy (26). The blockade of the PD-1 / PD-L1 pathway shows significant improvements with new agents used in lung cancer, renal cell carcinoma and melanoma (27). In immunotherapy, not only PD-L1 expression in tumor cells but also intratumoral and peritumoral immune cell density and PD-L1 expression in those immune cells are important (28).

In the literature, studies on breast cancer have shown that PDL1 expression is more common in lymphocytes that infiltrate the tumor rather than tumor cells. Its expression in lymphocytes infiltrating the tumor has been shown to be associated with prognosis (29-30). In our study, PD-L1 expression was detected in tumor cells in $12(6 \%)$ cases and in inflammatory cells in $45(22.5 \%)$ cases. A wide variety of positivity rates were found in the literature studies. This may be due to the differences in the antibody clones, scoring systems, sample size, and the positively evaluated cell type (tumor cell, inflammatory cell) (31-35).

Increased proliferative activity, high histological and nuclear grade and advanced stage are known to be poor prognostic criteria in breast cancer (36). In addition, PD-L1 expression in breast cancer is generally associated with the presence of tumor infiltrating lymphocytes and prognostic criteria such as high grade, triple negative histological type, and its expression is heterogeneous (37, 38). It is known that PD-L1 expression is detected as a negative prognostic factor in different tumors (39). In our study, PD-L1 expression in tumor cells was highest in medullary carcinoma/ /invasive carcinoma with medullary features. Also, PD-L1 expressions in both tumor cells and inflammatory cells were found to be significantly higher in histological grade 3 tumors. Similarly, in the study of Tawfik et al, PD-L1 expression was reported to be associated with higher grade and increased proliferative activity (31).

Maspin is a member of the serine protease family, which inhibits tumor invasion and angiogenesis, regulates apoptosis and shows tumor suppressive properties (13). In a study, it was reported that maspin expression decreased in the progression from in-situ ductal carcinoma to invasive carcinoma (40).

In our study, maspin expression positivity was found in 93 of 200 cases $(46.5 \%)$. Maspin positivity was found to be higher in invasive lobular carcinoma than other types of tumors. In some studies, it has been shown that there is a relationship between high tumor grade and maspin expression $(23,41)$.

Maspin expression is generally expected to be limited to cytoplasm. However, in a study by Pemberton et al., it was found to be expressed not only in the cytoplasm, but also in the nucleus (42). In our study, 73 (78.5\%) of 93 cases with positive maspin expression were detected only in cytoplasm and $20(21.5 \%)$ in both cytoplasm and nucleus. In addition, cytoplasmic maspin expression was significantly higher in medullary carcinoma / invasive carcinoma with medullary features cases $(p=0.001)$, but no relation was found between clinicopathological parameters and maspin staining. In a study, cytoplasmic staining was found in $21(63.4 \%)$ of 33 maspin positive cases and nuclear staining was found in 12 cases (36.6\%). Similar to our study, nuclear staining was always accompanied by cytoplasmic staining. In this study; higher grade, lymph node metastasis and perineural invasion were found to be associated with cytoplasmic maspin expression. Therefore, cytoplasmic maspin expression is thought to be associated with poor prognosis (43). In a study of Gurzu et al, In colorectal carcinomas, tumors in which cytoplasmic maspin staining is dominant have a better prognosis and nuclear dominance is associated with high aggressiveness (44). In our study, maspin expression was detected in invasive breast carcinoma cases, and it was found that there was an expression difference between tumor types. Maspin expression percentage was found to be higher in grade 3 cases than grade 1 cases $(p=0.031)$.

The density of lymphoid cells accompanying the tumor is important in terms of prognosis and treatment response (3). In our study, varying degrees of lymphocytic density were observed in different types of breast cancer. As the histological grade progressed from grade 2 to grade 3 , the lymphocytic density score increased. Our results also showed that there was a significant relationship between the degree of lymphocytic density and the expression of PD-L1 in tumor cells and inflammatory cells. However, more detailed studies are needed for the detection and importance of subtypes of these lymphoid cells.

Our results showed that there is PD-L1 expression in breast cancer. It was determined that PD-L1 expression was associated with prognostic parameters such as high grade, and triple negativity. This expression was detected in both tumor cells and inflammatory cells and was more intensely detected in inflammatory cells in accordance with the literature. Therefore, tumor cells should not be examined exclusively in the evaluation of PD-L1, and inflammatory cells should also be evaluated.

In conclusion, our study emphasizes the applicability and importance of immunotherapy based on the blockade of PD-1/PD-L1 axis in the treatment of breast cancer. In our study, breast cancer types other than invasive ductal carcinoma were also examined. As a result of the study, it was determined that a significant amount of maspin expression occurred in tumor cells, and the lymphocytic density accompanying the tumor was graded and examined. The results obtained and the literature information show that these parameters will make important contributions in predicting prognosis.

\section{References}

1. Eroglu M, Kokenek-Unal TD, Akin-Bali DF, Kirimlioglu SH. STAT3 expression is correlated with pathological stage in luminal subtypes of breast carcinoma. Bratisl Med J 2020; 121 (1): 51-61.

2. Burnet FM. The concept of immunological surveillance. Prog Exp Tumor Res 1970; 13: 1-27.

3. Cimino-Mathews A, Foote JB, Emens LA. Immune targeting in breast cancer. Oncology (Williston Park) 2015; 29 (5): 375-385.

4. Sznol M, Chen L. Antagonist antibodies to PD-1 and B7-H1 (PD-L1) in the treatment of advanced human cancer. Clin Cancer Res 2013; 19: 1021-1034.

5. Pardoll DM. The blockade of immune checkpoints in cancer immunotherapy. Nat Rev Cancer 2012; 12: 252-264.

6. Chen DS, Irving BA, Hodi FS. Molecular pathways: nextgeneration immunotherapy-inhibiting programmed death-ligand 1 and programmed death-1. Clin Cancer Res 2012; 18: 6580-6587. 
7. Parsa AT, Waldron JS, Panner A, Crane CA, Parney IF, Barry JJ et al. Loss of tumor suppressor PTEN function increases B7-H1 expression and immunoresistance in glioma. Nat Med 2007; 13: 84-88.

8. Taube JM, Anders RA, Young GD, Xu H, Sharma R, McMiller TL et al. Colocalization of inflammatory response with B7-H1 expression in human melanocytic lesions supports an adaptive resistance mechanism of immune escape. Sci Transl Med 2012; 4: 127-137.

9. Philips GK, Atkins M. Therapeutic uses of anti-PD-1 and anti-PD-L1 antibodies. Int Immunol 2015; 27: 39-46.

10. Azuma K, Ota K, Kawahara A, Hattori S, Iwama E, Harada Tet al. Association of PD-L1 overexpression with activating EGFR mutations in surgically resected nonsmall-cell lung cancer. Ann Oncol 2014; 25 (10): 1935-1940.

11. Thompson RH, Dong H, Kwon ED. Implications of B7-H1 expression in clear cell carcinoma of the kidney for prognostication and therapy. Clin Cancer Res 2007; 13 (2 Pt 2): 709-715.

12. Hino R, Kabashima K, Kato Y, Yagi H, Nakamura M, Honjo T et al. Tumor cell expression of programmed cell death-1 ligand 1 is a prognostic factor for malignant melanoma. Cancer 2010; 116 (7): 1757-1766.

13. Heit C, Jackson BC, McAndrews M, Wright MW, Thompson DC, Silverman GA et al. Update of the human and mouse SERPIN gene superfamily. Hum Genomics 2013; 7: 22.

14. Dabiri S, Moeini Aghtaei M, Shahryari J, Shamis Meymandi M, Amirpour-Rostami S, Foutohi Ardekani R. Maspin gene expression in invasive ductal carcinoma of breast. Iran J Pathol 2016; 11 (2): 104-111.

15. Maass N, Teffner M, Rösel F, Pawaresch R, Jonat W, Nagasaki K et al. Decline in the expression of the serine proteinase inhibitor maspin is associated with tumour progression in ductal carcinomas of the breast. J Pathol 2001; 195: 321-326.

16. Machowska M, Wachowicz K, Sopel M, Rzepecki R. Nuclear location of tumor suppressor protein maspin inhibits proliferation of breast cancer cells without affecting proliferation of normal epithelial cells. BMC Cancer 2014; 14: 142.

17. Marioni G, Staffieri A, Blandamura S. Maspin expression in head and neck carcinoma: subcellular localization matters. J Oral Pathol Med 2010; 39: 279-280.

18. Zou Z, Anisowicz A, Hendrix MJ et al. Maspin, a serpin with tumorsuppressant activity in human mammary epithelial cells. Science 1994; 263; 526-529.

19. Maass N, Hojo T, Rosel F, Ikeda T, Jonat W, Nagasaki K. Down regulation of the tumor suppressor gene maspin in breast carcinoma is associated with a higher risk of distant metastasis. Clin biochem 2001; 34 (4): 303-307.

20. Bertucci F, Finetti P, Cervera N, Charafe-Jauffret E, Mamessier E, Adelaide $\mathbf{J}$ et al. Gene expression profiling shows medullary breast cancer is a subgroup of basal breast cancers. Cancer Res 2006; 66 (9): 4636-444.

21. Ruffell B, Au A, Rugo HS, Esserman LJ, Hwang ES, Coussens LM. Leukocyte composition of human breast cancer. Proc Natl Acad Sci USA 2012; 109 (8): 2796-2801.

22. Herbst RS, de Marinis F, Jassem J, Spigel DR, Shankar G, Mocci S et al. Phase III clinical trials of atezolizumab compared with standard chemotherapy in PD-L1-selected chemotherapy-naive patients with advanced NSCLC. Ann Oncol 2015; 26: 105-106.

23. Lee MJ, Suh CH, Li Z-H. Clinicopathological significance of maspin expression in breast cancer. J Korean Med Sci 2006; 21: 309-314.

24. Folkl A, Bienzle D. Structure and function of programmed death (PD) molecules. Vet Immunol Immunopathol 2010; 134: 33-38.

25. Hodi FS, O'Day SJ, McDermott DF et al. Improved survival with ipilimumab in patients with metastatic melanoma. N Engl J Med 2010; 636: 711-723.
26. Mezache L, Paniccia B, Nyinawabera A, Nuovo GJ. Enhanced expression of PD- L1 in cervical intraepithelial neoplasia and cervical cancers. Mod Pathol 2015; 28: 1594-1602.

27. Terme M, Ullrich E, Aymeric L, Meinhardt K, Desbois M, Delahaye $\mathbf{N}$ et al. IL-18induces PD-1-dependent immunosuppression in cancer. Cancer Res 2011; 71 (16): 5393-5399.

28. Zhang M, Sun H, Zhao S et al. Expression of PD-L1 and prognosis in breast cancer: a meta-analysis. Oncotarget 2017; 8: 31347-31354.

29. Sun S, Fei X, Mao Y et al. PD-1(+) immune cell infiltration inversely correlates with survival of operable breast cancer patients. Cancer Immunol Immunother 2014; 63 (4): 395-406.

30. Schalper KA, Velcheti V, Carvajal D et al. In situ tumor PD-L1 mRNA expression is associated with increased TILs and better outcome in breast carcinomas. Clin Cancer Res 2014; 20 (10): 2773-2782.

31. Tawfik O, Kimler BF, Karnik T, Shehata P. Clinicopathological correlation of PD-L1 expression in primary and metastatic breast cancer and infiltrating immune cells. Hum Pathol 2018; 80: 170-178.

32. Soliman H, Khalil F, Antonia S. PD-L1 expression is increased in a subset of basal type breast cancer cells. PLoS One 2014; 9 (2): e88557.

33. Mittendorf EA, Philips AV, Meric-Bernstam F, Qiao N, Wu Y, Harrington $\mathrm{S}$ et al. $\mathrm{PD}-\mathrm{L} 1$ expression in triple-negative breast cancer. Cancer immunology research 2014; 2 (4): 361-370.

34. Baptista MZ, Sarian LO, Derchain SF, Pinto GA, Vassallo J. Prognostic significance of PD-L1 and PD-L2 in breast cancer. Hum Pathol 2016; 47(1): 78-84

35. Qin T, Zeng YD, Qin G, Xu F, Lu JB, Fang WF et al. High PD-L1 expression was associated with poor prognosis in 870 Chinese patients with breast cancer. Oncotarget 2015; 6 (32): 33972-33981.

36. Paksoy Senol E, Tasdelen I, Balaban Adim S, Ozkaya G, Tolunay S. A comparison of $\mathrm{Ki} 67$ proliferative index in primary tumor and axillary metastatic lymph nodes with length of survival in patients with breast cancer. Bratisl Lek Listy 2013; 114 (11): 645-649.

37. Bertucci F, Gonçalves A. Immunotherapy in Breast Cancer: The Emerging Role of PD-1 and PD-L1. Curr Oncol Rep 2017; 19: 1-11.

38. Zawlik I, Gablon N, Szymanska B et al. Immune checkpoints in aggressive breast cancer subtypes. Neoplasma 2016; 63 (5): 768-773.

39. Vrankar M, Zwitter M, Kern I, Stanic K. PD-L1 expression can be regarded as prognostic factor for survival of non-small cell lung cancer patients after chemoradiotherapy. Neoplasma 2018; 65 (1): 140-146.

40. Umekita Y, Ohi Y, Sagara $Y$ and Yoshida H. Expression of maspin predicts poor prognosis in breast cancer patients. Int J Cancer 2002; 100 : 452-455.

41. Lin Z, Liu Y, Sun Y, He X. Expression of Ets-1, Ang-2 and maspin in ovarian cancer and their role in tumor angiogenesis. J Exp Clin Cancer Res 2011; 30: 31 .

42. Pemberton PA, Tipton AR, Pavloff N, Smith J, Erickson JR, Mouchabeck ZM et al. Maspin is an intracellular serpin that partitions into secretory vesicles and is present at the cell surface. J Histochem Cytochem 1997; 45: 1697-1706.

43. Helal DS, El-Guindy DM. Maspin expression and subcellular localization in invasive ductal carcinoma of the breast: Prognostic significance and relation to microvessel density. J Egypt Natl Canc Inst 2017; 29: 177-183.

44. Gurzu S, Szentirmay Z, Popa D, Jung I. Practical value of the new system for Maspin assessment, in colorectal cancer. Neoplasma 2013; 60 (4): $373-383$.

Received May 2, 2020. Accepted July 27, 2020. 